\title{
Can a self-referral system help improve access to psychological treatments?
}

\author{
June SL Brown, Jed Boardman, Naureen Whittinger and Mark Ashworth
}

\begin{abstract}
Referrals for psychological treatment have been problematic for many years. Even though GPs have attempted to limit access into the small psychological treatment services, long waiting lists have developed which have deterred referrals and deferred psychological care. GPs have understandably been frustrated. In addition, the consultation rate for psychological problems is low when compared with the rate of identified mental health problems in population surveys. Possible reasons include patients failure to recognise the problem as psychological and thus not consulting one's GP, and/or the problem not being detected by the GP. While a self-referral system may be seen as a way of trying to allow non-consulters to receive treatment, this has been viewed with some scepticism since it may allow the 'worried well' to access already limited services. However, a study has shown that those self-referring to advertised psychological workshops had high levels of psychological morbidity and also were more representative of the population, in terms of ethnicity, than GP referrals. The government has set up the Increasing Access to Psychological Therapies (IAPT) programme to address some of the service shortfalls by expanding the provision of psychological therapists. Notably, the IAPT programme is allowing self-referrals such that any member of the public can access the service directly, bypassing general practice. Although not available at all the sites, this represents a radical shift from the present system in which access to talking therapy is generally only available through direct referral by the GP. The implications of this new development are discussed.

Keywords

access; psychological therapy; self-referral.
\end{abstract}

\section{INTRODUCTION}

Common mental health problems, mainly anxiety and depression, form a large proportion of the daily workload of GPs, ${ }^{1}$ and psychological therapies play a large part in their first-line management. ${ }^{2}$ However, because of their low capacity, access to psychological treatment services for individuals with these difficulties has often been variable and limited, with long waiting lists for these services. ${ }^{3}$ GPs have been understandably very frustrated by the capacity problem, as this has restricted treatment options for both the GP and the patient. In addition, while primary care services have offered short appointments to a large number of patients, described as 'low contact, high volume' services, ${ }^{4}$ psychological therapies have usually offered oneto-one interventions to relatively few patients, these being described as 'high contact, low volume' interventions. ${ }^{4}$

Common mental health problems are costly in both human and financial terms and this, combined with the poor availability of evidence-based treatments for depression and anxiety, has resulted in calls for an expansion. ${ }^{5}$ For this to happen, it has been estimated that more than 10000 new therapists will be required. ${ }^{5}$ In response, the Department of Health has developed the Improving

JSL Brown, BSc, MPsychol, PhD, senior lecturer in clinical psychology, institute of psychiatry; M Ashworth, DM, MRCP, FRCGP, clinical senior lecturer, King's College London.

J Boardman, BSc, PhD, FRCPsych, consultant psychiatrist; $N$ Whittinger, BSc, assistant psychologist, South London and Maudsley Foundation NHS Trust.

Address for correspondence

Dr June Brown, Psychology Department (PO77), Institute of Psychiatry, Kings College London, De Crespigny Park, London SE5 8AF. E-mail: June.Brown@kcl.ac.uk

Submitted: 26 July 2009; Editor's response: 13 October 2009; final acceptance: 23 February 2010.

(c)British Journal of General Practice 2010; 60: 365-371. 


\section{How this fits in}

Psychological services have been very limited in capacity. GPs have understandably become very frustrated as this has restricted treatment options for both the GP and the patient. Extra funding (and capacity) has been obtained through the Improving Access to Psychological Treatments (IAPT) programme and a self-referral system is being set up within the new (IAPT) programme to allow people to refer directly.
Access to Psychological Therapies (IAPT) programme, ${ }^{6}$ which aims to increase public access to effective psychological therapies for common mental health problems. With an investment of $£ 300$ million, it aims to train 3600 new therapists over 3 years, approximately one-third of the 10000 required, with the aim of creating more accessible therapy services. This programme was launched in 2005 with demonstration sites in Doncaster and Newham. In September 2008, the national roll-out of the programme began, aiming to cover approximately half of all primary care trusts (PCTs) over the following 3 years. These IAPT schemes will use a stepped-care approach offering both low- and high-intensity therapies. The highintensity approach will use evidence-based cognitive behavioural therapy (CBT) of up to 16 one-to-one sessions. The low-intensity approaches include computerised CBT, guided self-help, problem solving, and behavioural activation, matching better the 'low-contact, highvolume' approach of primary care.

Significantly, these new IAPT services will offer the option of self-referral. This enables people with selfdefined mental health problems to access mental health services in relatively large numbers, thus bypassing the need for GPs to always refer them. This option of self-referral may well be controversial. However, it may address a key finding from the National Psychiatric Morbidity Survey that about $70 \%$ of people with mental health problems do not present to their GP and therefore do not have access to psychological therapy. ${ }^{7}$ Even if patients do consult their GP, problems may not always be detected. Shortcomings in clinicians' skills in detecting mental health problems have been commonly reported. ${ }^{1,8}$ Additionally, there are often delays in seeking professional help before consulting GPs. Mean delays of 8 years $^{9}$ and 9.4 years $^{10}$ have been found for depression and anxiety problems. This paper will examine some of the reasons why people with mental health problems do not access help and receive treatment, and also how self-referral may help to improve access.

\section{RELUCTANT CONSULTERS}

\section{Attitudes towards GPs}

Several studies have reported that patients' reluctance to consult their physicians is related to how people believe their GPs will respond if they were to present with a mental health problem. Individuals may feel embarrassed about discussing their problems, ${ }^{11}$ or fear that they will be seen as weak and/or unable to cope. ${ }^{12}$ They may also have concerns that there is insufficient time to talk about problems. ${ }^{13,14}$

In addition, people believe that their GP would not be able to offer treatments other than antidepressant medication, which is commonly regarded with suspicion, ${ }^{15}$ despite medication also being perceived to be effective. ${ }^{16}$ Related to this, GPs are often viewed as being untrained to help, ${ }^{14,17}$ and less capable in dealing with emotional problems. ${ }^{18}$ On the other hand, people with depressive symptoms may choose not to consult because they do not see it as serious enough to justify a consultation. ${ }^{19}$

\section{The role of stigma}

The negative public perception of mental health problems may well affect the likelihood of disclosure of the problem to the GP, or result in delay before consultation, or indeed avoidance altogether of consultation. When compared with people with physical health problems, people with depression have tended to be seen as more emotionally unstable, less worthy of sympathy, and responsible for causing their own problems. ${ }^{20-22}$ Moreover, the general public are less willing to participate in social relationships with people with depression. ${ }^{23}$ Depression can be stigmatising and is often associated with decreased employment prospects, and expectations of poorer job performance. ${ }^{24}$

Given these widely held social attitudes, it is not surprising that several studies suggest stigma operates as a major barrier to help seeking. ${ }^{25,26}$ Thornicroft distinguishes between perceived stigma (expectations about the impact of stigma) and selfstigma (the internalisation of negative stereotypes). ${ }^{27} \quad$ Perceived stigma is strongly associated with low self-esteem and an avoidance of situations that have a high chance of leading to rejection. ${ }^{28}$ Of relevance here is Corrigan's suggestion that, in an attempt to distance themselves from negative stereotypes, a person suffering from depression may avoid the impact of labelling by denying their group status and avoiding mental health care. ${ }^{25}$ Alternatively, internalising negative stereotypes such as 'people with depression are weak' can lead to feelings of 
embarrassment about consulting professionals and also to delays in consulting. ${ }^{29}$

\section{Health beliefs}

Health beliefs or how individuals formulate health problems, and consequent decisions on appropriate courses of action, will inevitably affect decisions regarding whether or not to consult the GP. Many people view mental health problems as something they need to manage by themselves, rather than medicalise the problem ${ }^{30}$ by consulting the doctor. Medicalising a problem often has been defined as unilateral, as opposed to collaborative, decision making about health problems. It has also been defined as assuming there is a biological cause for a non-medical problem. Interestingly, GPs themselves question if they are right to prescribe antidepressants to people who have social problems. ${ }^{31}$ Meltzer et al reported in the National Psychiatric Morbidity Survey, that the most common response to how people deal with mental health problems was to try to cope with problems oneself. ${ }^{32}$ Thompson et al found that the most common reasons for not consulting were 'I thought it would go away by itself' $(27.2 \%)$ and 'I thought nothing could help' $(17.3 \%){ }^{10}$

Many people view mental health problems as a problem of everyday living that does not require the help of professionals. ${ }^{15}$ A large national survey in Germany reported that the general public felt depression resulted from social difficulties, such as unemployment, marital discord, family distress, and social isolation. ${ }^{33}$ Similarly, Lauber and colleagues reported that the most commonly perceived causes of mental health problems were relationship difficulties and occupational stress. ${ }^{34}$

How a problem is perceived also affects the type of 'treatment' sought. For example, many people have a preference for talking through their problems with others, ${ }^{35,36}$ or through spiritual support, ${ }^{37}$ or prayer. ${ }^{36}$ This may reflect the belief that they should be able to deal with such problems themselves, ${ }^{32}$ and would be more consistent with non-medical interventions such as counselling, fresh air, physical exercise, relaxation, and seeking social support from friends and family. ${ }^{33,34,37}$

This perception may explain the large role of informal help in mental health problems. ${ }^{38}$ When responders in a postal survey were asked to tick all the choices they would make, the most frequently chosen were their friends and family $(63.1 \%)$, followed by their GP (53.54\%). Notably, 14.25\% said they would not seek help from their GPs.

In an increasingly diverse UK population, the cultural beliefs of different groups will have a growing effect on the public's decisions to consult for common mental health problems. However, some ethnic groups are less likely to consult their GPs, as occurs with Africans ${ }^{39}$ and Asians. ${ }^{40}$ Even when people do attend their GP, detection rates for mental health problems are lower in ethnic minority groups. ${ }^{41,42}$

The stigma attached to being labelled as having mental health problems appears to be particularly high in certain cultures, for example in India, where schizophrenia is associated with low marriage prospects and a fear of rejection by neighbours. ${ }^{43}$ There are also cultural differences in beliefs towards psychological distress. A recent study of the attitudes of black African women in London who had suffered depression found that they thought depression was less serious, more short-lasting and less amenable to treatment compared with white British women. ${ }^{39}$ The ways in which people describe their problems also differ between cultures. For example, it is common for people from South Asia to express their problems as aches, pains, and sleep problems. ${ }^{44}$

\section{THE VALUE OF SELF-REFERRAL}

Self-referral to services for counselling and psychological therapies already exists in the voluntary and private sectors, as evidenced by the volume of advertisements in newspapers and periodicals, but this is relatively rare in the NHS and social care services.

Organising services with multiple levels of entry and service delivery, rather than the more traditional single referral gateway at the level of primary care into secondary care services, may help to increase access to psychological therapies. ${ }^{3}$ These entry points could include using practice nurses and selfhelp groups to deliver some low-intensity interventions. The opportunity to self-refer, especially to services run outside of office hours, may be particularly well suited to patients with busy lifestyles who find it difficult to visit their GP during surgery opening hours. An alternative entry point may also help to reduce the impact of 'medicalisation', ${ }^{30}$ so that mental health problems are perceived as less likely to automatically come within the domain of medical professionals. There appears to be less of a reluctance to seek help for physical health problems, compared to mental health problems (personal communication, E Warnock-Parkes, 2010). ${ }^{45}$ It is, therefore, not being argued that self-referral should be used across all specialties, but it is being suggested here because of a specific reluctance to seek help for mental health problems.

Two examples of psychological therapy services that have used a self-referral route have been 
published: one in Camberwell, south-east London, where large-scale, community-based psychoeducational groups for people with anxiety and depression have been run; ${ }^{46}$ the other in Newham, East London, which was set up as one of the first two pilot sites for the IAPT programme. ${ }^{47}$ These two services can illustrate the value of self-referral pathways for psychological therapies.

\section{Psycho-educational workshops}

Self-referral psycho-educational CBT workshops were originally set up in Birmingham and further developed in south-east London. ${ }^{46,48}$ They aimed to attract people with problems of depression and anxiety who may not have been able to access treatment through primary care. They also aimed to be responsive to those groups of people who may not traditionally enter treatment for mental health problems, such as people from black and minority ethnic groups. Publicity material was sent to GP surgeries, libraries, and other community centres, as well as through websites, to make the local community aware of these groups. Interested participants could call the telephone number or email the address given, in order to book themselves a place at the workshop.

While self-referral systems have been criticised for simply attracting the 'worried well', ${ }^{49}$ a crosssectional analysis of participants who did self-refer to these psycho-educational workshops revealed that almost three-quarters met criteria for International Classification of Diseases (ICD)-10 diagnoses, and had mean anxiety and depression scores well above average, ${ }^{50}$ suggesting that the self-referral system is successfully reaching those in need. Perhaps most fundamentally, almost onethird of self-referrers to the 'stress and self confidence' workshops had never previously consulted their GPs about their emotional problems. ${ }^{50}$ Those who had consulted their GP were significantly more distressed and depressed than those who had not consulted but, nevertheless, the distress and depression scores of non-consulters were still well above the clinical thresholds.

Additionally, these workshops have been shown to attract people from a range of backgrounds and they appear to be equally effective for self-referrers from differing areas of deprivation. ${ }^{48}$ They also appeal to groups that are traditionally more difficult to engage in services, such as the unemployed and people from black and minority ethnic groups. ${ }^{50}$ It is argued that using non-diagnostic labels of 'stress and self-confidence' enabled people with problems of depression and anxiety to receive help that fitted in more with the way in which they saw their problems as due to problems of living, such as work and relationship problems.

Given the government's commitment to 'promote mental health for all and combat discrimination against individuals and groups with mental health problems and promote their social inclusion', as asserted in the National Service Framework for Mental Health, ${ }^{51}$ this self-referral service may facilitate access to those who are particularly difficult to reach, and contributes to a more equitable NHS. While this service may seem resource intensive, given the context and immense burden, to both the individual and the economy, of mental health problems, it may prove to be costeffective and an evaluation along these lines would be useful. The health economic evaluation would need to cover a number of different aspects. As well as assessing the use of services, whether primary care or secondary care, it would need to assess the costs of absenteeism as well as 'presenteeism', ${ }^{52}$ whereby poorer productivity while experiencing mental health problems has often been shown to be costly. The cost of not being able to engage in normal activities also needs to be measured, as well as the economic costs to society through welfare benefits.

\section{Newham IAPT demonstration site}

The self-referral work described above, ${ }^{50}$ influenced the Department of Health to experiment with selfreferral in the two demonstration IAPT sites. While the Doncaster site decided not to offer self-referral as an option, the Newham service did offer a selfreferral route and 203 people $(22.8 \%)$ self-referred and 688 (77.2\%) were referred by GPs. ${ }^{47}$ In the final 3 months of the evaluation, the proportion of selfreferrers had increased to $42 \%$. Given that the service was very much in its early stages, it is not clear if this rate will be maintained in the long run but it is nevertheless an important indication of possible demand. One key finding of the evaluation was that GP referrals and self-referrals did not significantly differ in the severity of their psychological problems. Second, those who referred themselves more closely matched the ethnic mix of the community and were significantly more likely to be from black and minority ethnic groups than other referrals. Another finding of note was that social phobia and obsessive compulsive disorder (OCD) were found to be significantly more common among self-referrals than among GP referrals. This could suggest that people with these conditions are proportionately less likely to present to their GP, or that the GPs may detect problems but not refer them because they do not believe a referral to their local secondary or therapy services 
will be helpful. Relevant to this, there is also evidence to show that GPs are rational decision makers when referring for psychological therapies. ${ }^{53}$ Finally, while self-referrals had a slightly longer duration of their conditions (7.5 years versus 6.9 years), this difference was not statistically significant. ${ }^{47}$

\section{POSSIBLE DISADVANTAGES OF SELF-REFERRAL}

Easy access also means that those with less 'need' may also refer themselves. This could mean that those with relatively minor problems could come forward and overload the system. However, with the workshops, this is not a problem because of the large capacity available ( 25 places each month). The self-referral system may also allow more vocal and articulate participants to come forward, as there are anecdotal reports about this group assertively demanding services for relatively minor problems. However, the people coming into the local IAPT service, including self-referrers, have tended to have severe rather than $\mathrm{mild} / \mathrm{moderate}$ problems (personal communication, J Wingrove, 2010).

Steps are being taken to manage access into the IAPT system. Self-referral essentially means that people will not need to be referred by their GPs but can contact the IAPT service directly. However, once they self-refer, they are assessed, like everyone else. For example, in some IAPT services, all patients are being asked to complete a self-diagnosis assessment form so that their needs can be carefully assessed. Severity is rated using a variety of assessments from the IAPT Toolkit, ${ }^{54}$ as well as broader issues such as impact on the family and social factors such as unemployment. Good throughput is important in this system. 'Stepping up' patients with severe mental health problems who may need a combination of medication and psychological help to Step 4 is essential and requires good training in assessment so that patients are not retained inappropriately. Further, the pressure from IAPT for high throughput and high recovery rates is also likely to reduce the possibility of patients being inappropriately retained. Additionally, steps are being taken to focus the selfreferral system to socially excluded groups, such as unemployed people, who may otherwise not come forward. These excluded groups also include black and minority ethnic groups, including black Caribbean and African groups, who have been shown to often conceptualise their difficulties as social and interpersonal problems. ${ }^{39}$

\section{OTHER STEPS IN IMPROVING ACCESS}

Having a self-referral system does not necessarily provide accessible services for all groups. The language used in the service can be a major barrier for some. Access could be restricted if therapists can only speak English. Therefore, selection of bilingual therapists fluent in languages relevant to the area served should be considered.

As mentioned previously, 'low-intensity' workers provide treatments such as guided self-help, bibliotherapy, groups, computerised CBT, and exercise, which increase capacity and therefore access to psychological therapies. However, it is also important to match the type of skills to the needs of the local area. In some deprived areas, the majority of people coming into the service have moderate/severe problems, and more 'highintensity' workers as well as people to offer social care may be required.

How services are commissioned is also key in ensuring equitable provision, particularly to socially excluded groups. In this context, it would be important to involve key stakeholders to help design services that are appropriate for the local area. ${ }^{6}$ Need and priority should be carefully and clearly defined to maintain accessibility. Under IAPT, a key priority is to enable people on benefits, who frequently have mental health problems, to get back to work. In this way, the programme would eventually become self-funding.

\section{CONCLUSIONS}

The introduction of a self-referral route can be used to open up pathways to care, enabling people to access services of their choice without first having to consult their GP. It is clear the self-referral system does need to be linked to extra capacity, either through large-scale interventions or through the IAPT programme.

As well as allowing easier access, it can attract people who might not otherwise reach services. This may be because of reasons including reluctance to consult their GP, failure of the individual to recognise the psychological nature of their problems, or failure by the GP to detect the problems and recognise that the severity exceeds the threshold for referral. It also offers easier access for those who do not know where to go. While promising, the cost-effectiveness of this route needs evaluation.

Self-referral may also have disadvantages. People with relatively minor problems, or more vocal and articulate participants, may overuse limited services. Where this is the case, gatekeeping mechanisms to reduce the chances of this happening need to be, and are being, put in place.

However, self-referral is not the only way of improving access. Commissioners have been asked 
to design services that will improve access through increasing capacity (for example, 'low-intensity' therapists) as well as open access to groups that normally do not use services, such as black and minority ethnic groups. Effectively meeting the needs of the local population for psychological therapy, by providing accessible and high-quality services is a key requirement for commissioners in PCTs, ${ }^{6}$ and there is now more guidance about the local levels of service needed for a stepped-care approach in which CBT is specified as part of the pathway. ${ }^{55}$

In conclusion, the authors believe that the selfreferral route has major advantages for improved access to those who would otherwise not receive services. However, it needs to be structured so that the capacity can be well used by those in most need of services. Given this, it could work out extremely well and improve access for those who may not have been able to get access before, as well as those who have never thought of consulting.

\section{Competing interests}

The authors have stated that there are none.

\section{Acknowledgements}

Thanks to Shriti Raikundalia for her help with the compilation of this paper. June Brown is supported by the NIHR Specialist Biomedical Research Centre for Mental Health at the South London and Maudsley NHS Foundation Trust and Institute of Psychiatry, King's College London.

\section{Discuss this article}

Contribute and read comments about this article on the Discussion Forum: http://www.rcgp.org.uk/bjgp-discuss

\section{REFERENCES}

1. Goldberg D, Huxley P. Mental illness in the community: the pathway to psychiatric care. London: Tavistock, 1992.

2. National Institute for Clinical Excellence. Depression: the treatment and management of depression in adults: update. London: NICE, 2009.

3. Lovell K, Richards D. Multiple access points and levels of entry (MAPLE): ensuring choice, accessibility and equity for CBT services. Behav Cogn Psychother 2000; 28(4): 379-391.

4. France R. Behavioural cognitive therapy in the primary care setting: issues of organization. Clin Psychol Forum 1995; 76: 2-5.

5. Layard R. The case for psychological treatment centres. 2006. http://cep.lse.ac.uk/layard/psych_treatment_centres.pdf (accessed 25 Feb 2010).

6. Department of Health. Improving Access to Psychological Therapies (IAPT) Commissioning Toolkit. London: Department of Health, 2008.

http://www.dh.gov.uk/en/Publicationsandstatistics/Publications/Pub licationsPolicyAndGuidance/DH_084065 (accessed 25 Feb 2010).

7. Bebbington PE, Meltzer H, Brugha TS, et al. Unequal access and unmet need: neurotic disorders and the use of primary care services. Psychol Med 2000; 30(6): 1359-1367.

8. Thompson C, Kinmonth AL, Stevens L, et al. Effects of a clinicalpractice guideline and practice-based education on detection and outcome of depression in primary care: Hampshire depression project randomised controlled trial. Lancet 2000; 355(9199): 185-191.

9. Wang PS, Berglund P, Olfson M, et al. Failure and delay in initial treatment contact after first onset of mental disorders in the National Comorbidity Survey Replication. Arch Gen Psychiatry 2005;
62(6): 603-613

10. Thompson A, Issakidis C, Hunt C. Why wait? Reasons for delay and prompts to seek help for mental health problems in an Australian clinical sample. Soc Psychiatry Psychiatr Epidemiol 2004; 39(10): 810-817.

11. Paykel ES, Hart D, Priest RG. Changes in public attitudes to depression during the Defeat Depression Campaign. Br J Psychiatry 1998; 173: 519-522.

12. Wood F, Pill R, Prior L, Lewis G. Patients' opinions of the use of psychiatric case-finding questionnaires in general practice. Health Expect 2002; 5(4): 282-288.

13. Pollock K, Grime J. Patients' perceptions of entitlement to time in general practice consultations for depression: qualitative study. $B M$ J 2002; 325(7366): 687-692.

14. Cape J, McCulloch Y. Patients' reasons for not presenting emotional problems in general practice consultations. Br J Gen Pract 1999; 49(448): $875-879$.

15. Pill R, Prior L, Wood F. Lay attitudes to professional consultations for common mental health disorder: a sociological perspective. $\mathrm{Br}$ Med Bull 2001; 57: 207-219.

16. Croghan TW, Tomlin M, Pescosolido BA, et al. Americans' knowledge and attitudes towards and their willingness to use psychiatric medications. J Nerv Ment Dis 2003; 191(3): 166-174.

17. Outram S, Murphy B, Cockburn J. The role of GPs in treating psychological distress: a study of midlife Australian women. Fam Pract 2004; 21(3): 276-281.

18. Prior L, Wood F, Lewis G, Pill R. Stigma revisited, disclosure of emotional problems in primary care consultations in Wales. Soc Sci Med 2003; 56(10): 2191-2200.

19. Jewell D. September focus. Br J Gen Pract 2009; 59(566): 634

20. Ben-Porath DD. Stigmatization of individuals who receive psychotherapy: an interaction between help-seeking behavior and the presence of depression. J Soc Clin Psychol 2002; 21: 400-413.

21. Wadley VG, Haley WE. Diagnostic attributions versus labelling: impact of Alzheimer's disease and major depression diagnoses on the emotions, beliefs, and helping intentions of family members. Gerontol Psychol Sci 2001; 56B: 244-252.

22. Scambler G. Stigma and disease: changing paradigms. Lancet 1998; 352(9133): 1054-1055

23. Link BG, Phelan JC, Bresnahan M, et al. Public conceptions of mental illness: labels, causes, dangerousness, and social distance. Am J Public Health 1999; 89(9): 1328-1333.

24. Glozier N. Workplace effects of the stigmatisation of depression. $J$ Occup Environ Med 1998; 40(9): 793-800.

25. Corrigan P. How stigma interferes with mental health care. Am Psychol 2004; 59: 614-625.

26. Link BG, Phelan JC. Stigma and its public health implications. Lancet 2006; 367(9509): 528-529.

27. Thornicroft G. Discrimination against people with mental illness. Oxford: Oxford University Press, 2006.

28. Link BG, Struening EL, Neese-Todd S, et al. Stigma as a barrier to recovery: the consequences of stigma for self-esteem of people with mental illnesses. Psychiatr Serv 2001; 52(12): 1621-1626.

29. Barney LJ, Griffiths KM, Jorm AF, Christensen H. Stigma about depression and its impact on help-seeking intentions. Aust NZ J Psychiat 2006; 40(1): 51-54.

30. Tomes N. Patient empowerment and the dilemmas of late-modern medicalisation. Lancet 2007; 369(9562): 698-700

31. Macdonald S, Morrison J, Maxwell M, et al. 'A coal-face option': GPs' perspectives on the rise in antidepressant prescribing. $\mathrm{Br} J \mathrm{Gen}$ Pract 2009; 59(566): 658-659.

32. Meltzer H, Bebbington $\mathrm{P}$, Brugha T, et al. The reluctance to seek treatment for neurotic disorders. Int Rev Psychiatry 2003; 15: 123-128.

33. Angermeyer MC, Matschinger H, Riedel-Heller SG. Whom to ask for help in case of a mental disorder? Preferences of the lay public. Soc Psychiatry Psychiatr Epidemiol 1999; 34(4): 202-210.

34. Lauber C, Nordt N, Falcato L, Rossler W. Lay recommendations on how to treat mental disorders. Soc Psychiatry Psychiatr Epidemiol 2001; 36(11): 553-556.

35. Hugo C, Boshoff D, Traut A, et al. Community attitudes toward knowledge of mental illness in South Africa. Soc Psychiatry Psychiat Epidemiol 2003; 38(12): 715-719.

36. Givens JL, Houston TK, Van Voorhees BW, et al. Ethnicity and 
preferences for depression treatment. Gen Hosp Psychiatry 2007; 29(3): 182-191.

37. Jorm AF, Korten AE, Jacomb PA, et al. 'Mental health literacy': survey of the public's ability to recognize mental disorders and their beliefs about the effectiveness of treatment. Med J Aust 1997; 166(4): $182-186$.

38. Oliver MI, Pearson N, Coe N, Gunnell D. Help-seeking behaviour in men and women with common mental health problems: crosssectional study. Br J Psychiatry 2005; 186: 297-301.

39. Brown JSL, Bishop AJ, Prytys M, et al. How black African and white British women perceive depression: a pilot vignette study. Int J Soc Psychiatry 2010, doi:10.1177/ 0020764009357400 .

40. Hussain FA, Cochrane R. Depression in South Asian women living in the UK: a review of the literature with implications for service provision. Transcult Psychiatry 2004; 41(2): 253-270.

41. Maginn S, Boardman AP, Craig TKJ, et al. The detection of psychological problems by general practitioners: influence of ethnicity and other demographic variables. Soc Psychiatry Psychiatr Epidemiol 2004; 39(6): 464-471.

42. Odell SM, Surtees PG, Wainwright NWJ, et al. Determinants of general practitioner recognition of psychological problems in a multi-ethnic inner-city health district. Br J Psychiatry 1997; 171: 537-541.

43. Thara R, Srinivasan TN. How stigmatising is schizophrenia in India? J Soc Psychiatry 2000; 46(2): 135-141.

44. Pereira B, Andrew G, Pednekar S, et al. The explanatory models of depression in low income countries: listening to women in India. $J$ Affect Disord 2007; 102(1-3): 209-218.

45. Sansone RA, Dunn M, Whorley MR, Gaither GA. The acceptability of psychotropic vs. other medications among a small urban primary care sample. Gen Hosp Psychiatry 2003; 25(6): 492-494.

46. Brown JSL, Elliot SA, Boardman J, et al. Meeting the unmet need for depression services with psycho-educational self-confidence workshops: preliminary report. Br J Psychiatry 2004; 185: 511-515.

47. Clark DM, Layard R, Smithies R. Improving access to psychological therapy: initial evaluation of the two demonstration sites. Behav Res Ther 2009: 47(11): 910-920.

48. Brown JSL, Elliot SA, Butler C. Can large-scale self-referral psychoeducational stress workshops help improve the psychological health of the population? Behav Cogn Psychother 2006; 34: 165-177.

49. Katz SJ, Kessler RC, Frank RG, et al. The use of outpatient mental health services in the United States and Ontario: the impact of mental morbidity and perceived need for care. Am J Public Health 1997; 87(7): 1136-1143.

50. Brown JSL, Boardman J, Elliot SA, et al. Are self-referrers just the worried well? Soc Psychiatry Psychiatr Epidemiol 2005; 40(5): 396-401.

51. Department of Health. National Service Framework for Mental Health: modern standards and service models. London: Department of Health, 1999.

52. Boardman J, Parsonage M. Delivering the Government's mental health policies: services, staffing and costs. London: Sainsbury Centre for Mental Health, 2007.

53. Stavrou S, Cape J, Barker C. Decisions about referrals for psychological therapies: a matched-patient qualitative study. $\mathrm{Br}$ Gen Pract 2009; 59(566): 656-657.

54. IAPT Outcomes Toolkit 2008/9. http://www.iapt.nhs.uk/2008/01/30/improving-access-topsychological-therapies-iapt-outcomes-toolkit/ (accessed $25 \mathrm{Feb}$ 2010)

55. National Institute for Health and Clinical Excellence. Commissioning a service providing CBT for the management of common mental health problems.

http://www.nice.org.uk/usingguidance/commissioningguides/cogniti vebehaviouraltherapyservice/commissioning.jsp (accessed $25 \mathrm{Feb}$ 2010). 